Case Report

\title{
Prosthetically Guided Regeneration of Horizontal Bone Defect in Anterior M andible Using Allograft and Bio-resorbable Membrane
}

\author{
Harsh Desai ${ }^{1}$, Rakshith Hegde ${ }^{2}$, Manoj Shetty ${ }^{3}$ \\ ${ }^{1}$ Post Graduate Student, ${ }^{2}$ Professor, Department of Prosthodontics, ${ }^{3}$ Head, Department of Implantology, A.B. Shetty \\ $M$ emorial Institute of dental sciences, $M$ angalore.
}

*Corresponding Author : Harsh Desai, ${ }^{1}$ Post Graduate Student, Department of Prosthodontics, A.B. Shetty M emorial Institute of dental sciences, M angalore, M obile : +91 7899496260 E-mail : harsh35desai@ gmail.com

$\begin{array}{ll}\text { Received } & : 22.04 .2018 \\ \text { Review Completed } & : 30.04 .2018 \\ \text { Accepted } & : 05.05 .2018\end{array}$

Keywords : Allograft, Implants, Ridge augmentation

\begin{tabular}{|c|}
\hline Access this article online \\
\hline Quick Response Code \\
\hline
\end{tabular}

\begin{abstract}
Implantology has become an integral part of dentistry. Initially implant dentistry was surgically driven with implant placement thatwas determined by the available bone. Following this although osseo integration was achieved, the outcome many a times didn't fulfil the basic function anaesthetics. The correction after implant placement with help of angulated abutments in anterior region will produce undesirable aesthetics. Prosthetically driven implant placement will help in the overall function and aesthetic. This case report describes managing a horizontal defect in the anterior mandibular region with help of allogenic graft material and establishing the prosthetically driven approach.
\end{abstract}

\section{Introduction}

Experimental and clinical studies show osseointegration to be highly predictable, and dental implants currently represent a reliable means for restoring dental function in partially and completely edentulous patients. ${ }^{[1,2,3]}$ The practice of oral implantology is not new or recent anymore with reports of root form implants of over 50 years are present in the literature, treatment planning on the other hand has undergone significant evolution in recent times.

With the advent of CBCT and other diagnostic tools the concept of 'surgically and anatomically driven implant placement' where implant placement was determined by the location of available bone, it has shifted towards 'restoration driven implant placement'. Following the initial concept where osseo integration was the primary outcome of the surgery, prosthodontic rehabilitation was a challenge due to angulation of implants because of which the function and aesthetic both were compromised.
This case report describes a case in which horizontal augmentation was done to place implant in prosthodontically driven position and reduce the angulated load on the bone as well as get acceptable aesthetic and functional result.

\section{Classification}

A classification of horizontal defects according to prosthetically driven diagnostic protocol and surgical options, was suggested by Matteo Chiapasco and Paolo Casentini ${ }^{4}$ according to which,

Class I: In class 1, no discrepancy exists between the ideal position of the implant(s), the implant-supported prosthetic unit(s) and the alveolar bone anatomy.

Class II: In class 2, a moderate horizontal deficit is present. In this situation, implant(s) can be placed in the correct prosthetically driven position but a simultaneous hardtissue-augmentation procedure is indicated. 
Class III: In class 3, a significant horizontal deficit is present and the residual bony anatomy does not allow the implant to be placed in an ideal prosthetic position and achieve primary stability.

Class IV: In Class 4, a combined horizontal and vertical defect is present.

\section{Case Report}

Treatment Planning

A 24 year old patient reported to the OPD of Department of prosthodontics with missing 31, 41(Figure 1).

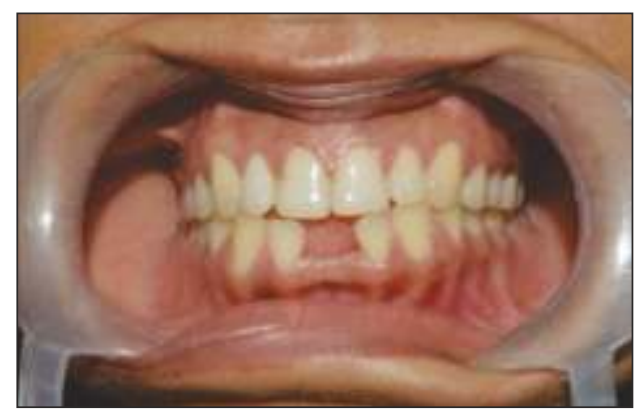

Figure 1 : Missing 31,41

The teeth were missing since one year following trauma. CBCT was done to evaluate the bone. (Figure 2)

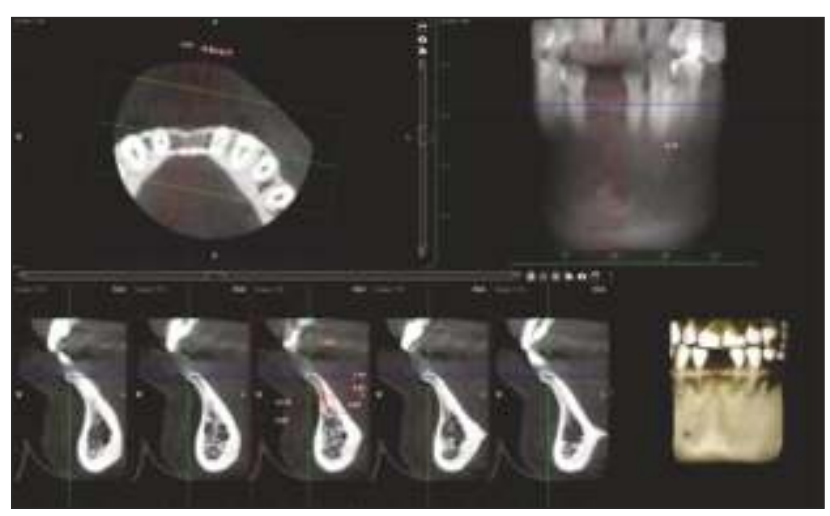

Figure 2 : $C B C T$ showing bone height and width

The bone height was found to be adequate but width (4.80 $\mathrm{mm}$ ) was compromised. Patient was informed about the situation and different treatment options were explained. Patient opted for implant supported fixed prosthesis. Since the space was inadequate for two implants, single implant was planned to replace both 31,41 . The planning was to get the correct angulation of implant so as the straight abutment can be used during the second stage prosthetic phase. For which wax up was done and surgical template was made. Prosthetic planning thus was one of the major factors in determining the surgical procedure.

Patient had class 2 defect according to the criteria. This meant that hard tissue grafting was needed. The grafting material selected was allogenic bone grafting material (Rocky Mountain) with bio-resorbable membrane (Periocol-GTR). Based on the CBCT a $3.5 \mathrm{~mm}$ diameter 11 $\mathrm{mm}$ long implant (Ankylos, Dentsply) wasused.

\section{Surgical Phase}

After following the sterilization and disinfection protocol, Local Anaesthesia was infiltrated on the surgical site. Midcrestal incision was given to expose the site and was extended vertically on the labial side to expose the defect (Figure 3). Sequential osteotomy was done (Figure 4) and implant was torqued.
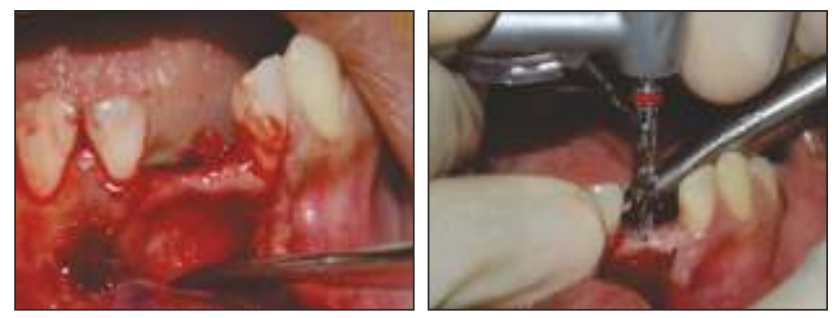

Figure $3 \& \mathbf{4}$ : Full thickness flap raised and sequential ostotomy After which defect was grafted with allergenic particulated graft (Rocky Mountain) and was covered with the GTR membrane (Pericol-GTR) (Figure 5).

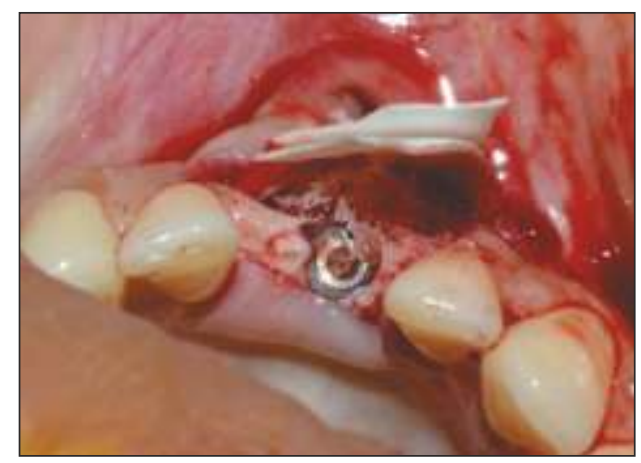

Figure 5 : Graft and membrane

Non-resorbable interrupted sutures (vicryl, 3-0) were given for the proper approximation of flap. Patient was asked to continue the antibiotic (Augmentin 625) and analgesic (Enzoflame) for 5 days.

After 7 days patient was recalled for suture removal and 
follow up in which no significant finding was noticed.

Prosthetic Phase

After 4 months provisional restoration was made and cemented with provisional cement (Free genol, GC)for bone training. Patient was recalled after 2 months for final restoration. $\mathrm{CBCT}$ was taken to evaluate bone healing which was found to be adequate. (Figure 6)

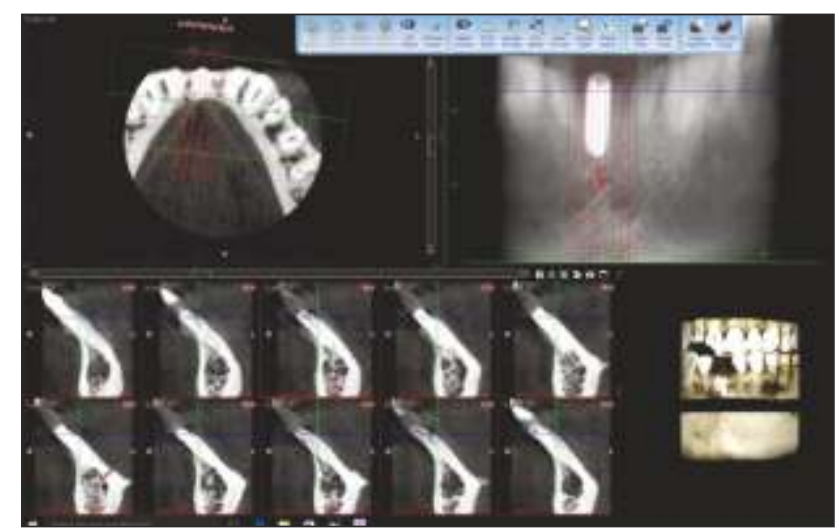

Figure 6 : CBCT for bone evaluation

Gingival Former was placed and patient was recalled after a week. Closed tray implant level impression wasmade in the subsequent appointment with light body and putty consistency addition silicone (Aquasil,Dentsply) (figure 7) and cast was poured.

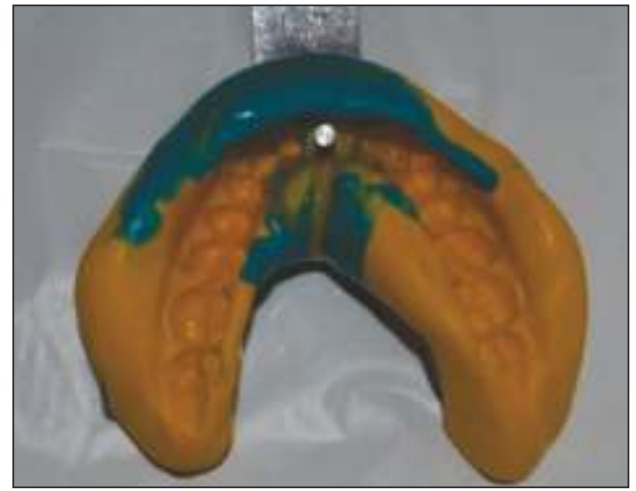

Figure 7 : Closed tray abutment level impression

According to gingival thickness and available space 0 degree abutment (Ankylos regular abutment 0.75/6 mm) was selected using abutment selection kit (Ankylos Abutment selection kit). (Figure 8)

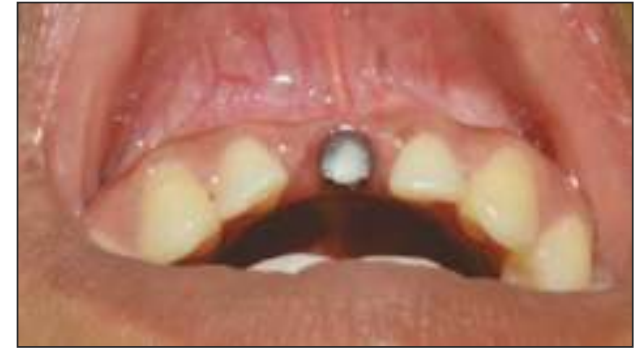

Figure 8 : 0 degree abutment

PFM prosthesis was cemented in the next appointment (figure 9) using zinc phosphate cement (De Trey Zinc, Dentsply).

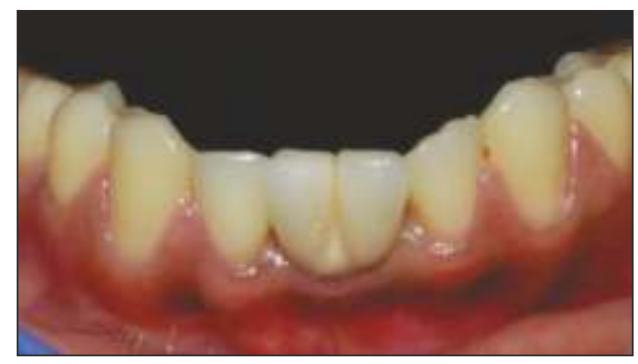

Figure 9 : PFM prosthesis

The prosthesis satisfied the criteria of function and aesthetic. Although emergence profile was not natural but since the smile didn't expose the area patient was satisfied with the result. (Figure 10)

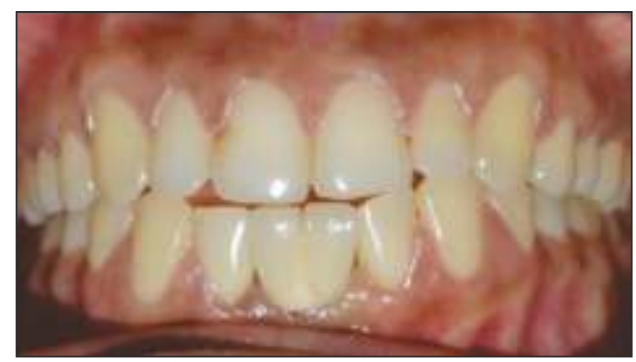

Figure 10 : Final prosthesis

\section{Discussion}

According to the classification, class 2 defect a moderate horizontal deficit is present but implant can be placed in the correct prosthetically driven position but a simultaneous hard-tissue-augmentation procedure is indicated. The main therapeutic options in class 2 cases involve implant placement associated with guided boneregeneration techniques using autogenous particulate bone and/or alloplastic materials in association with a semi permeable barrier (resorbable or non resorbable). 
In this case alloplastic bone material and bio-resorbable membrane was used to place the implant. Guided bone regeneration with a resorbable membrane is the preferred technique for the treatment of peri-implant defects such as a dehiscence or fenestration and even in class 3 cases when advanced horizontal atrophy is present ${ }^{[5]}$ The protection of the membrane allows the bone defect to be populated by blood vessels and osteogenic cells coming from the bone marrow cavities and the bone surface ${ }^{[6]}$ and excludes any epithelial/soft-tissue infiltration of the area.

The benefits are the technique is 'user friendly' and requires a low degree of surgical skill andsurgery can usually be performed under local anaesthesia.

\section{Conclusion}

With the advent of new diagnostic procedure the concept

\section{References}

1. Adell R, Eriksson B, Lekholm U, Branemark PI, Jemt T. A long-term follow-up study of osseointegrated implants in the treatment of totally edentulous jaws. Int J Oral M axillofac Implants 1990: 5: 347-359.

2. Buser D, M ericske-Stern R, Bernard JP, Behneke A, Behneke N, Hirt HP, Belser UC, Lang NP. Long-term evaluation of non-submerged ITI implants. Part I: 8-year life table analysis of a prospective multicenter study with 2359 implants. Clin Oral Implants Res 1997: 8: 161-172.

3. Chiapasco M, Gatti C, Rossi E, Markwalder T, Haefliger W. Implantretained mandibular overdentures with immediate loading: a retrospective study on 226 consecutive cases. Clin Oral Implants Res 1997: 8: 48-57.

4. Chiapasco M, Casentini P. Horizontal bone-augmentation procedures in implant dentistry: prosthetically guided regeneration. Periodontology 2000. 2018 Feb 25.

5. Urban IA, Nagursky H, Lozada JL, Nagy K. Horizontal ridge augmentation with a collagen membrane and a combination of particulated autogenous bone and anorganic bovine bone-derived mineral: a prospective case series in 25 patients. Int J Periodontics Restorative Dent 2013: 33: 299- 307.

6. Bosshardt DD, Schenk RK. Biologic basis of bone regeneration. In: Buser D, editor. 20 years of guided bone regeneration. Chicago, IL: Quintessence Publishing, 2009: 15-45. of prosthetically driven restoration is gaining credibility. This concept is particularly important in situations in which the residual bone, as a result of atrophy, sequelae of periodontal disease, trauma, etc. is reduced in volume in the horizontal and/or vertical dimension.

Regarding horizontal alveolar defects, although reduceddiameter implants are available and may allow acceptable prosthetic results, the present trend is to re-create, where possible, ideal conditions in terms of bone volume and surrounding soft-tissue quality. The approach' prosthetically guided regeneration' in this case report is based on the classification given by Chiapasco and Casentini and allows for the reconstruction of lost alveolar and soft-tissue contours as well as implant placement in position which permit prosthetic restoration an optimal outcome of function and esthetic. 